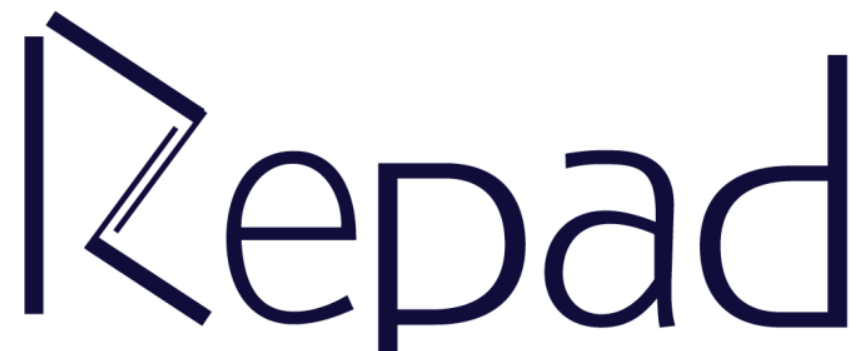

Vol. 1, N. 1 Dezembro/2017

Revista Estudos e

Pesquisas em Administração

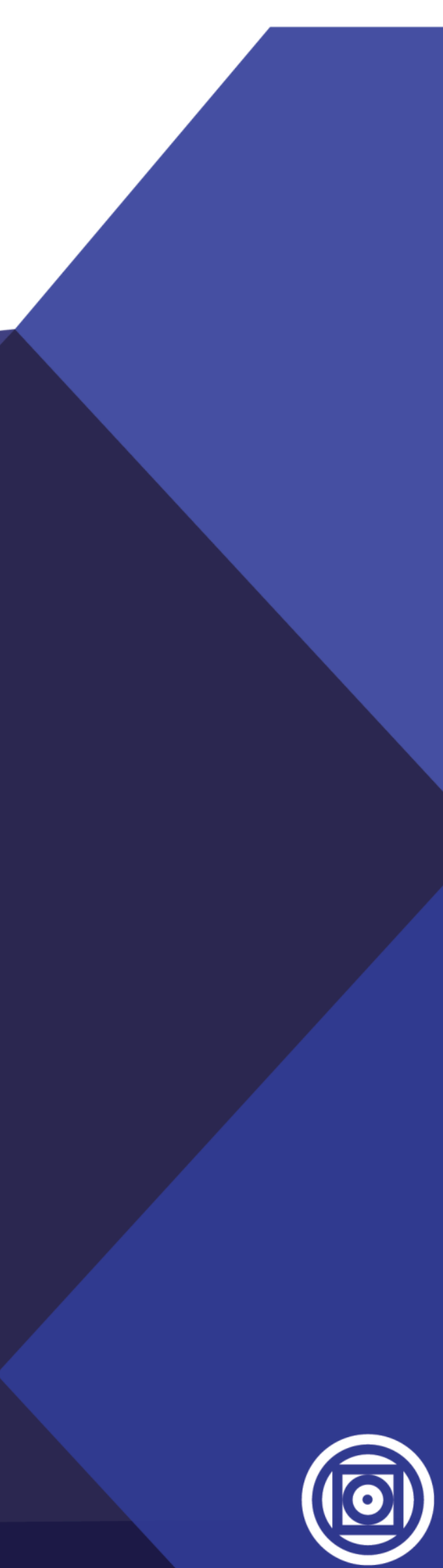




\title{
OS IMPACTOS AMBIENTAIS: Um estudo na Área de Preservação Permanente (APP) da Rodovia Do Peixe, Rondonópolis - MT
}

Juliana Maciel Latorraca

Universidade Federal de Mato Grosso/Câmpus Rondonópolis

Fernanda Pereira Silva Universidade Federal de Mato Grosso/Câmpus Rondonópolis http://orcid.org/0000-0003-2224-2943

Débora Aparecida Silva dos Santos Universidade Federal de Mato Grosso/Câmpus Rondonópolis

Michelle Salles da Silva Universidade Federal de Mato Grosso/Câmpus Rondonópolis

\section{RESUMO}

As áreas de preservação permanente têm a função de preservar recursos hídricos, paisagens, biodiversidades, estabilidades geológicas, entre outros. Desta forma, pretende-se saber quais os impactos negativos gerados a partir da construção da Rodovia 471, denominada de Rodovia do Peixe, situada no munícipio de Rondonópolis, Mato Grosso. Nesta condição, a presente pesquisa teve como objetivo analisar os impactos socioambientais negativos, da Rodovia do Peixe, a partir do povoamento às margens do Rio Vermelho. Pesquisa do tipo qualitativo, descrita pelo método exploratório e descritivo, tratados pelo estudo de caso, tendo em vista a coleta de dados, a partir de visita técnica in loco e entrevistas, com registros fotográficos, realizados em maio de 2015. Os resultados obtidos mostram que a APP está degradada em função da ação antrópica, como: pesqueiros fora dos limites tolerados pelo Código Florestal Brasileiro; poluição rio; assoreamento do rio; destruição do solo e a contaminação das águas. Acerca disso, requer políticas públicas de planejamento, fiscalização e recuperação, das áreas degradadas seguindo as normas legais.

Palavras-chave: Impactos ambientais, Área de Preservação Permanente, Ação Antrópica.

ENVIRONMENTAL IMPACTS: A study in the Permanent Preservation Area (APP) of "Rodovia do Peixe", Rondonópolis - MT

\begin{abstract}
The areas of permanent preservation have the function of preserving water resources, landscapes, biodiversity, geological stability, among others. Hence, the present study intends to find what were the negative socio-environmental impacts caused by the construction of "Rodovia do Peixe", located in Rondonópolis, Mato Grosso. Thus, the article consisted in analyzing the negative socio-environmental impacts of "Rodovia do Peixe", after the settlement alongside the Red River. Qualitative type research, described by the exploratory and descriptive method, treated by the case study, considering the data collection from a technical visit in loco and interviews, with photographic records, carried out in May of 2015. The results obtained in this study showed that the APP is degraded due to anthropic actions, such as: fishing outside
\end{abstract}


the limits tolerated by the Brazilian Forest Code; river pollution; river silting; soil destruction and water contamination. It requires public policies of planning, inspection and recovery of the degraded areas following the legal rules.

Keywords: Environmental impacts, Areas of permanent preservation, anthropic action.

\section{INTRODUÇÃO}

A Política Nacional de Meio Ambiente (PNMA), instituída pela Lei nº.938/81, tem como um dos principais instrumentos de efetividade de proteção ambiental a criação e proteção de espaços territoriais especialmente protegidos. A Comissão Mundial de Áreas Protegidas da União Internacional para a Conservação da Natureza (IUCN) define área protegida como o espaço de terra ou de mar definida especificamente para a proteção e a manutenção da diversidade biológica, dos recursos naturais e culturais associados e gerida por meios legais ou outros que sejam efetivos (CAPPELLI, 2011).

Neste contexto, a degradação antrópica na natureza tem gerado intenso processo de exploração (explotação) dos recursos naturais, o que requer certa apreensão da sociedade, quanto as medidas socioambientais governamentais para orientar as ações do homem na preservação do meio natural, protegendo, assim, meio ambiente. Tal situação é vivenciada no Município de Rondonópolis, em que são necessárias medidas efetivas e conscientes por parte dos proprietários ou arrendatários no processo de compensação ou mitigação dos impactos ambientais, sendo estas, consequências diretas dos acordos públicos, para liberação da Área de Preservação Permanente (APP), como é o caso da habitação de ambientes pesqueiros as margens do Rio Vermelho, da Rodovia Estadual 471.

Contribuindo com a preocupação ambiental em função da perspectiva de aplicação das normas de gestão ambiental, no artigo 225, da Constituição Federal-CF de 1988, prevalece a garantia de um meio ambiente ecologicamente equilibrado para todos e o estabelecimento de normas para preservação e proteção, capazes de restringir as atividades antrópicas. Ao criar o conceito de Área de Preservação Permanente (APP), bem como do legislador em resguardou diretamente a flora, a fauna, os recursos hídricos e os valores estéticos, de maneira a garantir o equilíbrio do meio ambiente e a consequente manutenção da vida humana e da qualidade de vida do homem em sociedade, deixando determinadas áreas a salvo do desenvolvimento econômico e da degradação, posto que as florestas e demais formas de vegetação guardam íntima relação com os elementos naturais citados (FARIAS, 2007).

Nesse sentido, Leuzinger (2010) ressalta que, os espaços territoriais, especialmente, protegidos se definem como qualquer área sobre a qual incida proteção jurídica de alguns ou de todos os bens ambientais presentes e, são, portando, gênero, comportando duas espécies, as Unidades de Conservação (UC), previstas na Lei 9.985/2000, e os espaços de proteções específicos, agrupam todos os demais espaços ambientais previstos em normas esparsas, os quais não sejam as unidades de conservações. Ainda, a mesma legislação trata dos espaços de proteção específica, que agrupam todos os demais espaços ambientais, previstos em normas esparsas, os quais não sejam as unidades de conservação.

Em consonância com o atual Código Florestal, Lei n 12.651 de 2012, com base no Art. $3^{o}$, a Área de Preservação Permanente (APP), compreende-se a uma região protegida, coberta ou não por vegetação nativa, com a função ambiental de preservar os recursos hídricos, a paisagem, a estabilidade geológica e a biodiversidade, facilitar o fluxo gênico de fauna e flora, proteger o solo e assegurar o bem-estar das populações humanas. Nas APP's são proibidas ações antrópicas, sejam essas ações um desmatamento ou uma construção. Ainda, 
aplicabilidade das alíneas da Lei 4.471 de 1965 , no art. $2^{\circ}$ do Código Florestal, que estabelece a impossibilidade de edificar à margem de rio, e de outros reservatórios de água até certo limite. Isso ocorre em face das legislações municipais menos restritivas no que diz respeito ao estabelecimento das áreas de preservação permanente.

No entanto, percebe-se que os governantes das três esferas públicas (Federal, Estadual e Municipal), vêm desrespeitando o ordenamento jurídico em função da premissa do crescimento econômico, ao restringir tal evidencia, limitando os recursos naturais as margens do Rio Vermelho, denominada de Rodovia Estadual 471. Este fato é ainda mais alarmante, em se tratando da degradação e da poluição das águas, ainda mais, com mortalidade de peixes, sendo este um crime gravíssimo previsto pela legislação.

Logo, é importante o estudo da ação antrópica na APP da Rodovia do Peixe, a fim de que sejam analisados os impactos negativos ocasionados a partir da explotação dos recursos naturais, na tentativa de propor ações de mitigação ou compensação para preservação do meio ambiente, considerando os diversos fatores e agentes envolvidos nessa relação. Tendo em vista, que a Rodovia do Peixe se localiza no município de Rondonópolis-MT, sendo um empreendimento construído em uma APP povoada, conforme liberação Estadual para construções de pesqueiros às margens do Rio Vermelho. Contudo, com as ações antrópicas ocasionam violações diretamente do ordenamento jurídico em relação a Área de Preservação Permanente. Nota-se ainda, que os impactos ambientais antrópicos geram degradação na fauna. e vegetações nativas as margens do rio veem prejudicando a fauna e flora.

Estas ações de povoamento às margens dos rios tornaram-se essas áreas em espaços urbanos, uma vez que com as áreas urbanas os ciclos hidrológicos sofrem fortes alterações em detrimento de alteração da superfície; canalização dos cursos d'água; aumento do escoamento superficial; retirada das matas ciliares; e aumento do material sólido disposto pela população (MORAES et al., 2002). Desta forma, além da intensa degradação dos recursos hídricos e ocupações e construções irregulares nas áreas de preservações, ocorrem retrações dos espaços determinados, como legal. Consequentemente, as áreas verdes, ao serem historicamente manejadas de forma inadequada, deixam de cumprir seu papel no contexto urbano e ambiental.

O estudo em questão, pesquisou os pesqueiros construídos as margens da Rodovia do Peixe localizada no município de Rondonópolis-MT, cuja área é registrada como área de preservação permanente (APP), povoada conforme liberação Estadual para construções de pesqueiros às margens do Rio Vermelho. Porém, devido as ações antrópicas e as violações diretas do ordenamento jurídico, esta APP, causam diversos impactos ambientais. Nestes impactos ambientais a partir das ações antrópicas geradas; ocasionam depredação e desmatamento da vegetação nativa, que prejudica a fauna, flora; aumentos dos processos erosivos, assoreamentos, enchentes, devastações das pragas e doenças, decorrentes da eliminação de resíduos sólidos domésticos em lugares indevidos. Isto se deve, por causa da falta de gestão dos entes públicos em fiscalizar, conscientização e aplicar as diretrizes estabelecidas na legislação, as normas regulamentadoras. Resultando assim, em pequenos espaços denominados de pesqueiros, com grande quantitativo de moradores por área povoadas as margens do rio, tornaram essas áreas em espaços urbanos.

Uma vez que com as áreas urbanas os ciclos hidrológicos sofrem fortes alterações em detrimento de alteração da superfície; canalização dos cursos d'água; aumento do escoamento superficial; retirada das matas ciliares; e aumento do material sólido disposto pela população (MORAES et al., 2002). Desta forma, além da intensa degradação dos recursos hídricos e ocupação e construção irregular em áreas de preservação, observa-se que há uma retração do espaço determinado como legal. Consequentemente, as áreas verdes, ao serem historicamente manejadas de forma inadequada, deixam de cumprir seu papel no contexto urbano e ambiental. 
Em face ao exposto e entendendo que a Rodovia do Peixe é uma APP, pretende-se saber a seguinte indagação: quais os impactos negativos gerados a partir da construção da Rodovia 471, denominada de Rodovia do Peixe, situada no munícipio de Rondonópolis, Mato Grosso? Nesta condição, a presente pesquisa teve como objetivo analisar os impactos socioambientais negativos, da Rodovia 471, (Rodovia do Peixe), a partir do povoamento as margens do Rio Vermelho, situada no munícipio de Rondonópolis, Mato Grosso, com base nas variáveis de meio biótico, biológico e antrópico, a partir das percepções de oito proprietários/inquilinos dos pesqueiros.

\section{REFERENCIAL TEÓRICO}

\section{ÁREAS DE PRESERVAÇÃO PERMANENTES (APP)}

Em consonância com a Lei $n^{\circ} 12.651$, de 25 de maio de 2012, que dispõe sobre a proteção da vegetação nativa e dá outras providências, tendo como objetivo o desenvolvimento sustentável. O novo Código Florestal (2012, p. 14); Lei No 4.771, DE 15 DE SETEMBRO DE 1965 em seu Art. 12, "garante que as florestas existentes no território nacional e as demais formas de vegetação nativa são bens de interesse comum a todos os habitantes do País", exercendo-se os direitos de propriedade com as limitações que a legislação em geral estabelece. Conceitualmente, as áreas de Preservação Permanente, consiste:

[...] área protegida, coberta ou não por vegetação nativa, com a função ambiental de preservar os recursos hídricos, a paisagem, a estabilidade geológica e a biodiversidade, facilitar o fluxo gênico de fauna e flora, proteger o solo e assegurar o bem-estar das populações humanas (BRASIL, 2012, s/p.).

De tal modo, para preservação destas áreas aplicadas medidas de restrição, com o intuito de restringir evitar o uso da terra e dos recursos naturais nela disponíveis, com objetivo de se ter um meio ambiente ecologicamente equilibrado indissociado do desenvolvimento socioeconômico e o respeito à dignidade humana. Colaborando com isso, ainda há a CONAMA n 369 , de 28 de março de 2006, é responsável por permitir a supressão da vegetação em APP em determinadas situações, desde que seja para configurado para fins de utilidade pública, interesse social ou baixo impacto social:

Art. $1^{\circ}$ Esta Resolução define os casos excepcionais em que o órgão ambiental competente pode autorizar a intervenção ou supressão de vegetação em Área de Preservação Permanente-APP para a implantação de obras, planos, atividades ou projetos de utilidade pública ou interesse social, ou para a realização de ações consideradas eventuais e de baixo impacto ambiental (CONAMA, 2006, p. 94).

Assim, para utilização das APP's, há impreterivelmente, o uso da legislação e as normas ambientais, que garantem e determinam instrumentos para a adequada gestão ambiental já estabelecida pelo homem. No entanto, apesar de previstas nas leis ambientais brasileiras, as APPs são áreas vulneráveis almejadas para os mais diversos fins econômicos para o desejado desenvolvimento socioeconômico. 
O clima de Rondonópolis é Tropical Chuvoso, com um clima quente e úmido, com estações bem definidas, uma chuvosa e outra seca (AMARAL et al., 1982 apud VASCONCELOS et al., 1999).

Quanto a paisagem que pode ser percebida pelo homem encontra-se no domínio dos cerrados e cerradões há a predominância de interflúvios e vertentes suaves dos mais diversos tipos de planaltos regionais, assim as florestas de galerias, por vezes, constituem- se em forma de corredores contínuos de matas ou podem também quando se tem um fundo aluvial homogêneo e alongado, as matas formam-se como corredores florestais (AB'SABER, 2003; SILVA, 2015).

O período seco, que ocorre no meio do ano, faz com que os cursos d'água principais e secundários afinem ou desapareçam, sendo o tropicalismo regional marcado por períodos de chuvas alternados com estações de seca, preservando intensamente os padrões de perenidade os cursos d'água regionais, permanecendo, ainda, os canais de escoamento lateral dos chapadões que formam uma linha fina de água que atravessa a seca no meio do ano (AB'SABER, 2003).

A fauna se aproxima claramente da vegetação natural composta por Tamanduá, Tatu, Lobo Guará, Lobinho, Antas, Veados, Preás, Pacas, Cutias, Garças, Lagartos, Cobras e outras (SILVA, 2015).

\section{RODOVIA DO PEIXE - MT 471}

A Rodovia Estadual MT 471, popularmente conhecida como Rodovia do Peixe, foi inaugurada após a pavimentação da Av. Daniel Clemente e da rodovia Isabela Carrasqueira Smozinski, as margens do Rio Vermelho com extensão de $23 \mathrm{Km}$, com intuito de ligar a área urbana à zona rural de Rondonópolis (DETRAN, 2009). Ademais, o objetivo desta rodovia consiste no projeto de multiplicador para integrar diversas atividades econômicas e turísticas do município, melhorando a acessibilidade as regiões, facilitando a comunicação dos bairros com o centro da cidade (SEFAZ, 2009).

Ainda, esta Rodovia possibilita significativa melhora na infraestrutura dos bairros, pois "aproximadamente $80 \%$ da população vive de um lado do rio, contudo, trabalha no distrito industrial" (SIQUEIRA, 2015). A Figura 1 apresenta o mapa de localização da MT 471.

Conforme Figura 1, é evidente a importância que a Rodovia MT 471, possui ao ser o principal elo entre as cidades mato-grossenses, bem como a integração para melhorar o acesso aos produtores e proprietários dos sítios situados nesta localidade, contemplado pela rica passagem socioambiental, unindo a fauna e flora em um espaço socioambiental para melhoria da qualidade de vida da sociedade a que circunda.

Figura 1: Mapa de Localização da Rodovia MT 471. 


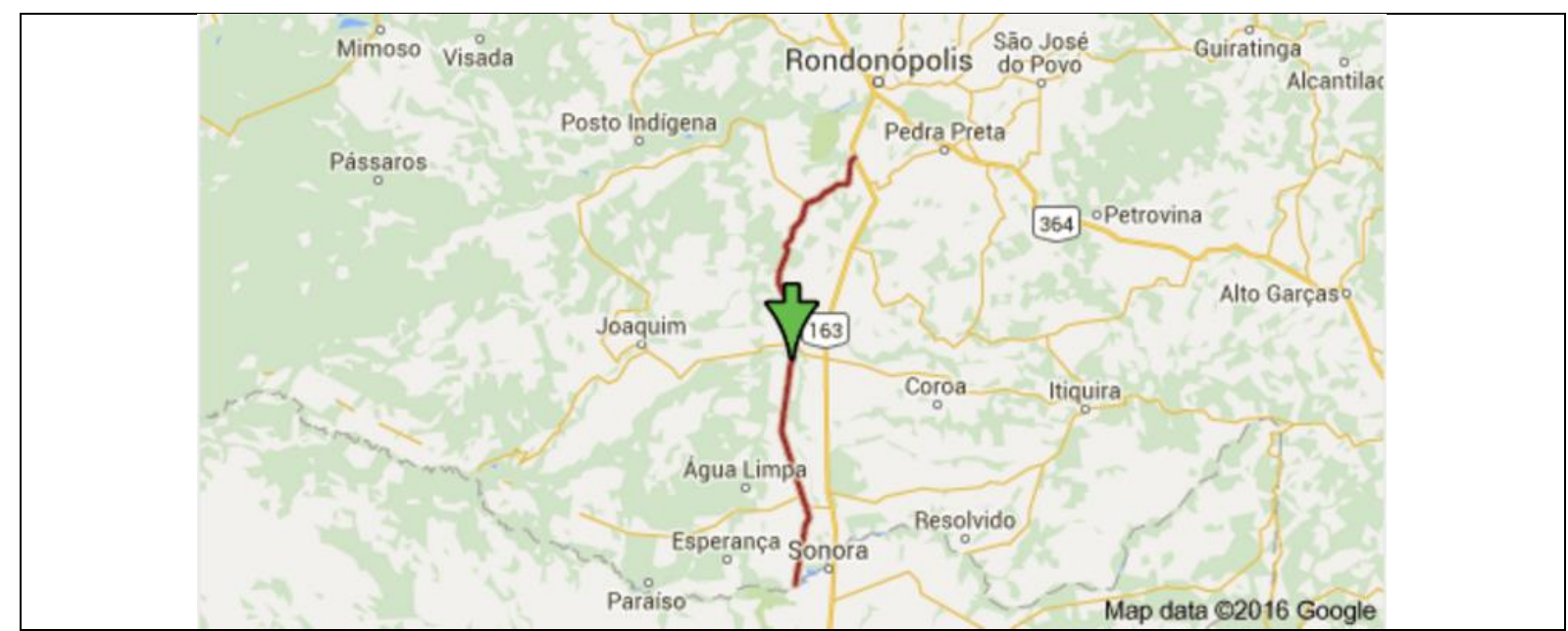

Fonte: Google Mapas, 2016.

\section{POVOAMENTO NAS PROXIMIDADES DOS RIOS E SEUS IMPACTOS SOCIOAMBIENTAIS}

Conforme a história, em todo o processo de desenvolvimento da humanidade as margens dos rios sempre foram às regiões propicias ao povoamento para as mais diversas utilidades, dentre elas a construção de residências, plantação, comércio e até mesmo a indústria. A urbanização, como a conhecemos, engendra diversos impactos sócios ambientais:

No limiar do século XXI, a questão urbana confunde-se com a questão ambiental. [...]. As características da urbanização brasileira fazem com que esse processo seja, não só, um fator gerador de problemas ambientais, mas, um problema ambiental em si. A urbanização modifica todos os elementos da paisagem: o solo, a geomorfologia, a vegetação, a fauna, a hidrografia, o ar e, até mesmo, o clima. Desse modo, a urbanização cria, não só novas paisagens, mas novos ecossistemas (BRAGA, 2003, p. 114).

Esta proliferação dos espaços urbanos, na percepção de Moraes et al. (2002), modificam os ciclos hidrológicos com fortes alterações da superfície, o aumento do escoamento superficial; a retirada das matas ciliares e o aumento do material sólido disposto pela população.

Além de intensa degradação dos recursos hídricos devido a ocupação irregular em áreas de preservação, observa-se que as mesmas sofrem uma retração de seu espaço como determinado pelo Código Florestal (2012), as influências políticas e da sociedade no meio biótico. Contribuindo com essa perspectiva:

A ocupação das margens de nascentes e rios, também chamadas de áreas ciliares ou ripárias, por atividades agropecuárias exerce efeito negativo sobre a qualidade e quantidade de água disponível para consumo (SCHÄFFER et al., 2011, p. 13).

Por fim, as áreas verdes, estão em crescente degradação devido à ação do homem na natureza, historicamente manejadas de forma inadequada, deixam de cumprir seu papel no contexto urbano e ambiental. Benjamim (2010 apud SCHÄFFER et al., 2011) afirma que há pessoas que ignoram os antecedentes dos desastres ambientais e os consequentes prejuízos sócio econômicos: 
Reclamações de que é impossível para os agropecuaristas ou moradores urbanos cumprir as determinações da legislação, que as leis são feitas nos gabinetes de Brasília sem levar em consideração a realidade das diferentes regiões do Brasil, que a legislação vai inviabilizar a agricultura brasileira, que as pessoas precisam dos espaços das margens de rios e encostas para construir suas moradias, entre outras alegações (BENJAMIM, 2010 apud SCHÄFFER et al., 2011, p. 31).

Além disso, de acordo com o Ministério do Meio Ambiente - MMA (2016), para minimizar os efeitos de urbanização nas APP's, deve-se instituir uma gestão integrada para aperfeiçoar as políticas ambientais voltadas para recuperação, manutenção, monitoramento e fiscalização das APP's, como:

- articulação de estados e municípios para a criação de um sistema integrado de gestão de Áreas de Preservação Permanente urbanas, incluindo seu mapeamento, fiscalização, recuperação e monitoramento;

- apoio a novos modelos de gestão de APP urbanas, com participação das comunidades e parcerias com entidades da sociedade civil;

- definição de normas para a instalação de atividades de esporte, lazer, cultura e convívio da população, compatíveis com a função ambiental dessas áreas.

Acerca disso, percebeu-se que o Governo Federal feriu a própria além do Código Florestal, bem como a Resolução do CONAMA 001/2006, supracitadas, trata que as atividades dos pesqueiros têm causado diversos impactos ambientais negativos e sem a fiscalização efetiva do poder público. Assim, na matriz de indicadores de impactos ambientais, Oliveira (2016) salienta os impactos aos meios físico, biológico, antrópico, conforme Quadro 1, ocasionam problemas com a implantação dos pesqueiros, a seguir:

Quadro 1: Indicadores de Impactos ambientais na área de Estudo.

\begin{tabular}{|l|l|}
\hline Meio & Impactos \\
\hline Meio físico & - Erosão e instabilidade das margens \\
& - Assoreamento de nascentes e cursos d'água \\
& - Diminuição da recarga de águas \\
\hline Meio biológico & - Diminuição ou perda de habitats naturais. \\
& - Diminuição ou perda de biodiversidade. \\
& - Alteração do ecossistema natural. \\
& - Introdução de animais domésticos. \\
& - Estabelecimento de espécies vegetais exóticas. \\
- Ameaça às espécies raras.
\end{tabular}

Fonte: adaptado a partir de Oliveira, 2016.

Ainda, de acordo com Souza e Oliveira (2014), no Mato Grosso reduziu a ocupação dos solos, reduzindo drasticamente a cobertura vegetal das matas nativas do cerrado. Esta redução foi ocasionada por causa do desmatamento, que na visão de Dotto (2009) ocorreu por causa dos desmatamentos das matas ciliares e nas áreas de nascentes, tal fato ainda, se agrava quando 
somado a ocupação do solo para a agropecuária na região sudeste de Mato Grosso, que desta maneira, com o processo de modernização da agricultura houve a introdução de um número alarmante de produtos agrotóxicos nas lavouras, que atingem diretamente os recursos hídricos.

Para implantação dos corredores ecológicos em uma APP, deve-se avaliar os impactos ambientais, dos meios físicos, meios ecológicos e meios socioeconômicos, conforme impera a Resolução do CONAMA 001/1986, em seu Art. $6^{\circ}$ que assim define:

a) o meio físico - o subsolo, as águas, o ar e o clima, destacando os recursos minerais, a topografia, os tipos e aptidões do solo, os corpos d'água, o regime hidrológico, as correntes marinhas, as correntes atmosféricas;

b) o meio biológico e os ecossistemas naturais - a fauna e a flora, destacando as espécies indicadoras da qualidade ambiental, de valor científico e econômico, raras e ameaçadas de extinção e as áreas de preservação permanente;

c) o meio socioeconômico - o uso e ocupação do solo, os usos da água e a socioeconomia, destacando os sítios e monumentos arqueológicos, históricos e culturais da comunidade, as relações de dependência entre a sociedade local, os recursos ambientais e a potencial utilização futura desses recursos.

No tocante a isso, o conceito de degradação ambiental, conforme a Lei da Política Nacional do Meio Ambiente, em seu art. $3^{\circ}$, há alterações de formas adversas as características do meio ambiente. Ainda, na visão de Sánchez (2008), essas ações causam impactos ambientais negativos com prejuízos à saúde, às atividades sociais, bem como o bem-estar das pessoas), as atividades econômicas e à biosfera, etc., dada a complexidade da degradação ambiental que causam alterações adversas nos processos, funções ou componentes ambientais, ou na qualidade ambiental.

\section{FUNDAMENTAÇÃO METODOLÓGICA}

A abordagem da pesquisa idealizada tem caráter qualitativo, uma vez que envolve a obtenção de dados descritos, extraídos pelo contato direto com o entrevistador com a situação adequada (MARTINS; CAMPOS, 2004).

Desta forma, o processo metodológico compreende em uma pesquisa de campo, exploratória e descritiva, assim descritas. O método de pesquisa exploratório envolve levantamento bibliográfico, entrevistas com pessoas que tiveram experiências práticas com o problema pesquisado (MENEZES, 2005) e fotos para mostrar os impactos ocasionados. Na pesquisa descritiva se descreve aos fatos e fenômenos de determinada realidade, que permitem a análise dos estudos descritivos e correlatos, estudos de casos, análise documental, estudos causais comparativos e outros (TRIVINÕS, 1987). Com isso, o tipo de pesquisa fundamentouse em um estudo de caso, uma vez que "visa conhecer em profundidade o como e o porquê de uma determinada situação que se supõe ser única em muitos aspectos, procurando descobrir o que há nela de mais essencial e característico" (FONSECA, 2002, p. 33).

$\mathrm{O}$ universo e as amostras da pesquisa embasaram-se por meio do estudo na Rodovia do Peixe situada no município de cidade de Rondonópolis, Estado de Mato Grosso e a amostras da pesquisa baseou-se nas percepções dos proprietários dos pesqueiros, a partir de uma pesquisa realizada em maio de 2015, através de uma visita em loco nos pesqueiros situados as margens do Rio Vermelho, são eles: 3 pesqueiros comerciais, 5 pesqueiros domésticos. 
Por conseguinte, as estratégias de coletas de dados basearam-se em entrevistas, bem como as visitas in loco realizadas nas propriedades dos pesqueiros. Para isso, propôs-se as análises das variáveis de impactos ambientais, dentre elas: Meio biótico- erosão e instabilidade das margens; assoreamento de nascentes e cursos d'água. Meio biológico- diminuição ou perda de habitats naturais; diminuição ou perda de biodiversidade; alteração do ecossistema natural; introdução de animais domésticos; estabelecimento de espécies vegetais exóticas e ameaças às espécies raras. Meio antrópico- alteração na qualidade de vida da população; diminuição da qualidade estética e paisagística; aumento de pressão antrópica sobre os recursos naturais dos remanescentes/áreas de preservação e ocupação irregular; diminuição da recarga das águas.

\section{QUANTO A DESCRIÇÃO DA APP NO RIO VERMELHO}

A Rodovia Estadual MT 471, denominada de Rodovia do Peixe é uma área de preservação Permanente, uma vez que se compreende a uma longa faixa de vegetação as margens do Rio Vermelho, compreende-se a 50 (cinquenta) metros para os cursos d'água que possuem entre 100 (cem) e 200 (duzentos) metros de largura; igual à distância entre as margens para os cursos d'água com largura superior a 200 (duzentos) metros (CÓDIGO FLORESTAL BRASILEIRO - Lei n 7.511, de 1986). Desta forma, o Código Florestal - Lei 12.727 de 2012, em seu Art. 4- considera-se Área de Preservação Permanente (APP), em zonas rurais, as seguintes denominações: no item I, "refere-se as faixas marginais de qualquer curso d'água natural perene e intermitente, excluídos os efêmeros, desde a borda da calha do leito regular, em largura mínima" para as seguintes metragens:

“a) 30 (trinta) metros, para os cursos d'água de menos de 10 (dez) metros de largura; .b) 50 (cinquenta) metros, para os cursos d'água que tenham de 10 (dez) a 50 (cinquenta) metros de largura; c) 100 (cem) metros, para os cursos d'água que tenham de 50 (cinquenta) a 200 (duzentos) metros de largura; d) 200 (duzentos) metros, para os cursos d'água que tenham de 200 (duzentos) a 600 (seiscentos) metros de largura; e) 500 (quinhentos) metros, para os cursos d'água que tenham largura superior a 600 (seiscentos) metros"(BRASIL, Código Florestal - Lei 12.727 de 2012).

Com base no exposto, os limites das faixas marginais do curso d'água do Rio vermelho (rio médio) é uma faixa marginal compreendida entre as terras indígenas da Tadarimana e o bairro denominado de Tereza Cristina. Esta região é uma APP que abrange o bioma do cerrado e o Pantanal, cujos faixas marginais encontram-se entre 50 a 600 metros de larguras. Nas suas margens encontram-se pesqueiros que dos pesqueiros está desacordo com as normas ambientais.

Figura 2: Fotos do Rio Vermelho com margens de vegetação natural. 


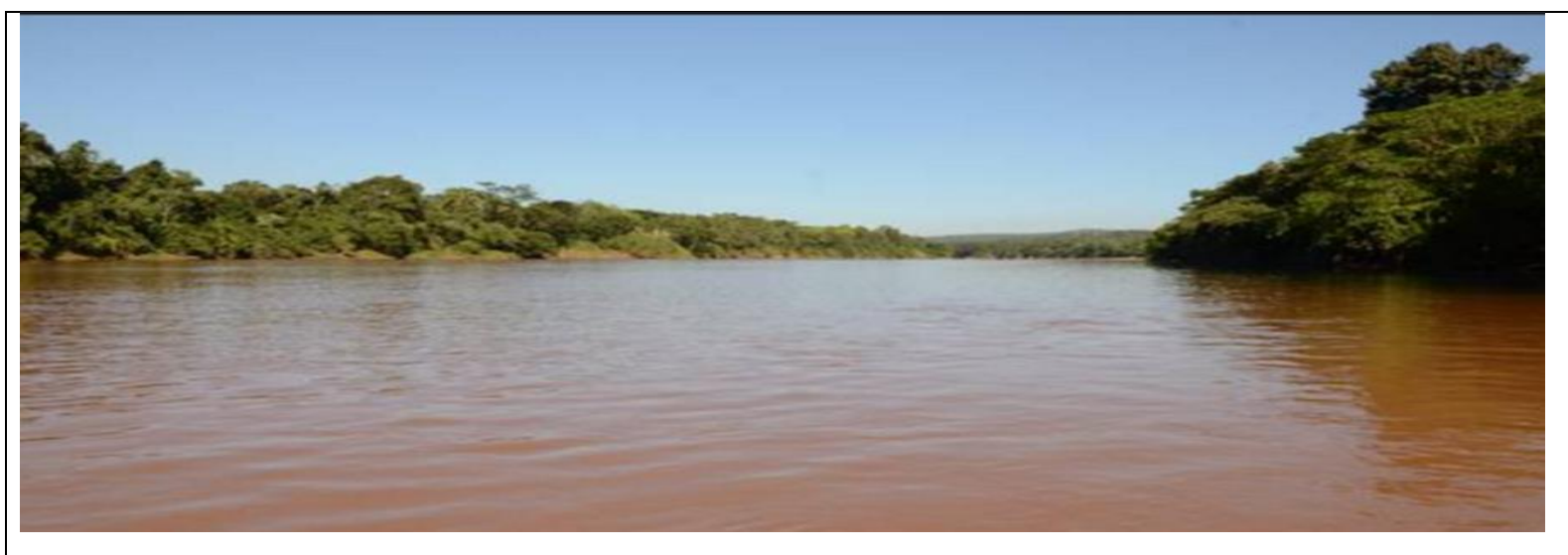

Fonte: Extraída pelos autores, 2016.

O Munícipio de Rondonópolis desenvolveu- se no entorno do Rio Vermelho, tanto que o corpo do Rio Vermelho-MT, que atravessa toda a extensão da cidade, sendo possível observar devido sua área plana e ao longo de suas margens sofre desmatamento, devido as ocupações das margens do rio e que é impactada drasticamente com as construções de estradas e edificações, conforme é demonstrado na Figura 3.

Figura 3: Região do Rio Vermelho em Rondonópolis.

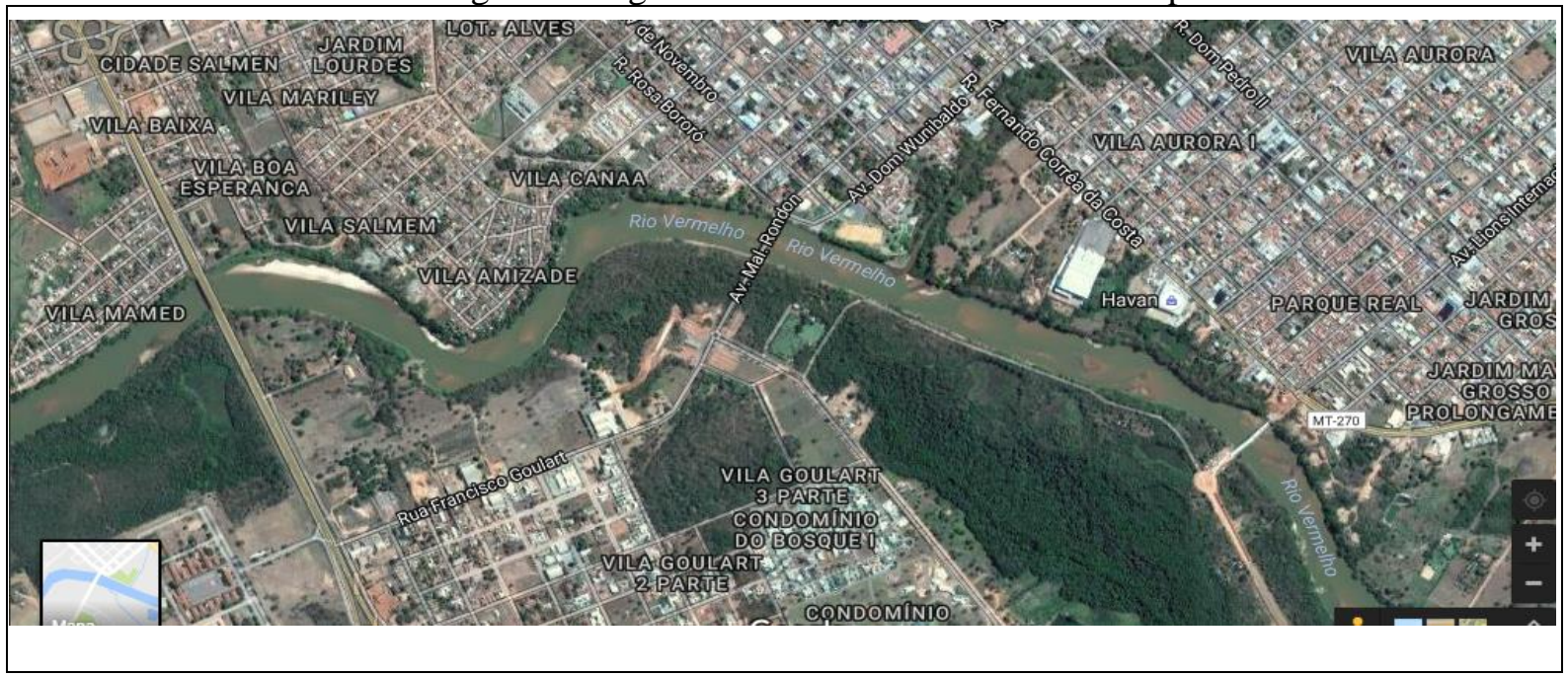

Os pesqueiros ficam ao longo $23 \mathrm{Km}$ da Cidade de Rondonópolis, as margens do Rio Vermelho, com quantitativo de 100 (cem) pesqueiros, sendo estes, particulares e comerciais, bem como áreas turísticas, como a Cidade de Pedra, clubes e entre outros. Os tamanhos dos pesqueiros variam, entre 30 a 300 metros de cumprimento. Em face disto, percebeu-se a grande aglomeração de pesqueiros às margens do rio, que vem ocasionando diversos impactos socioambientais (CACHEFFO, 2016).

\section{RESULTADO DA PESQUISA}

Os resultados de pesquisa sedimentaram-se na relação de impactos negativos na Rodovia do Peixe e a qualidade da água do Rio Vermelho, com base nas informações, a seguir: 
Nos pesqueiros da Rodovia do Peixe detectou-se diversos impactos socioambientais no solo, na água, nas matas ciliares, a partir das variáveis de meio biótico, biológico e antrópico, como representados, a seguir:

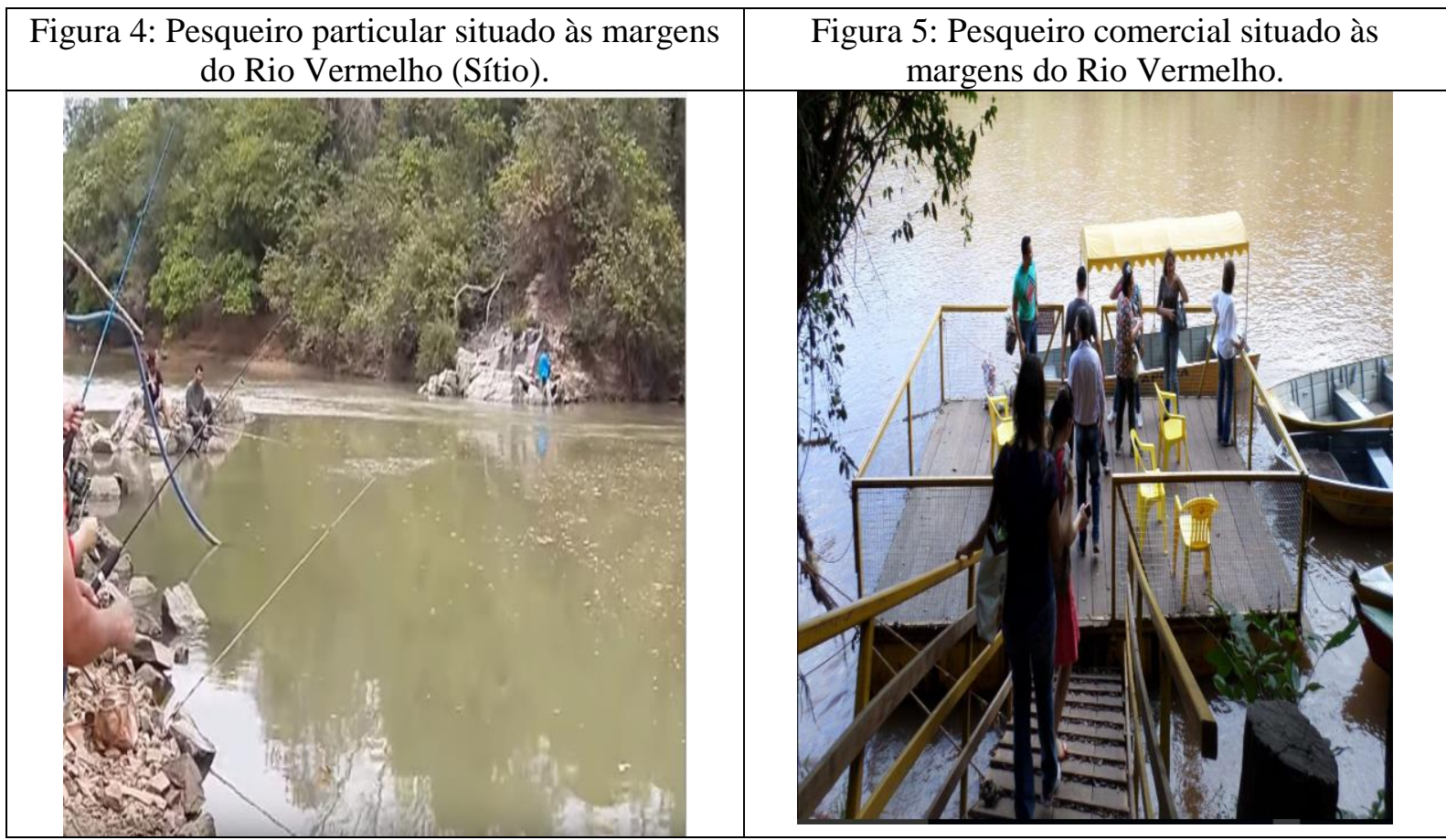

Fonte: Extraídas pelos autores, 2016.

De acordo com as figuras acima, todos os pesquisados destacaram que a partir da construção dos pesqueiros, o rio vem pendendo sua beleza e exuberância, sendo em alguns pontos destacados pelo uso indiscriminado de resíduos. Além disto, a frente apresenta os impactos do meio biótico com as seguintes constatações:

$\mathrm{Na}$ Figura 1 apresentou o desequilíbrio ambiental causado pelo meio antrópico, observou-se o uso generalizado de sevas com iscas para pegar os peixes ao longo do tempo modifica a coloração da água esverdeadas em alguns pontos; cheiros desagradáveis em 15 pontos visitados, deixa, uma vez que esta matéria orgânica se decompõe na água e grande parte dela fica no fundo rio, poluição no fundo do rio; erosões do solo ao longo do rio é perceptível por todos os pesquisados em vários trechos das margens dos rios

Ademais, detectou-se instabilidades nas margens do rio, decorrentes de uso de barcos de pesca e seus derramamentos de óleos e lixos dos pesqueiros poluem drasticamente os recursos naturais; assoreamento do rio e nascentes nos cursos d'água encontram-se com grandes impactos negativos após o ambiente humanizado. Estas ações foram destacadas por todos os pesquisados e pesquisados e requerem urgência para não ultrapassam os limites da natureza e assim necessitam de conscientização ambiental dos pesqueiros e visitantes. Neste sentido, de acordo com os pesquisadores as estruturas dos pesqueiros às margens do Rio Vermelho vêm acarretando diversos impactos ambientais, sem preocupação e conscientização do meio ambiente, como poluição, degradação ambiental, devastação da mata nativa e destruição dos barrancos dos rios ocasionando assoreamento no rio, destruição do solo e contaminação das águas.

Quanto aos impactos do meio biológico podem-se perceber as seguintes variáveis, são elas: quanto a diminuição ou perda de habitats naturais, entre os pesquisados, todos, relataram 
diminuição destes recursos, uma vez que é uma região muito explorada por pesqueiros e visitantes e com grande concentração de pessoas e, ainda, metade dos pesquisados disseram que raramente veem espécies nativas do cerrado naquela região. A diminuição ou perda de biodiversidade constatou-se mudanças estruturais ao longo das margens do Rio Vermelho, como perda das fauna e flora, mas não relataram especificamente. Diante desta interface há necessidade de controlar o uso do solo e estabelecer critérios racionais de ocupação de uma região (ROCHA citado por SOARES et al., 2016).

Por consequente, essas mudanças na fauna e flora, qualidade dos recursos hídricos, assoreamentos dos rios em diversos trechos e entre outros, ocasionam-se alterações no ecossistema natura. A introdução de animais domésticos perceptível na metade dos pesqueiros pesquisados, uma vez que servem como seguranças para as propriedades. As ameaças aos estabelecimentos de espécies vegetais exóticas e ameaças às espécies raras, mais da metade dos pesquisados, disseram que raramente se vê e geralmente, quando as pessoas as encontram tratam de extrair de seu habitat natural. Faz-se necessário a avaliação dos Impacto ambientais, segundo (MARINHO et al., 2012) citado por Soares et al. (2016, p. 622), devido a necessidade do equacionamento do conflito entre a necessidade de apropriação e utilização dos recursos naturais e a manutenção do padrão aceitável da qualidade ambiental, por meio do estabelecimento de procedimentos e atividades sequenciadas. Quanto os meios antrópicos, no que concerne as alterações da qualidade de vida da população, todos os pesquisados relataram que a região corresponde a área de lazer próximo à cidade e somente 2 destes, residem entre 20 a 25 anos, naquela localidade e disseram que depois da povoação as margens do Rio Vermelho, veem a cada dia, modificação dos recursos naturais do ecossistema. Consonante a isso, a diminuição da qualidade estética e paisagística, pôde-se perceber em qualquer base do ecossistema, como apresentado nas (Figura 1 e 2), bem como os relatados pelos participantes, como por exemplo, na fauna, flora, solo, água e entre outros. Quanto ao aumento de pressão antrópica sobre os recursos naturais dos remanescentes/áreas de preservação e ocupação irregular as margens do Rio vermelho de acordo os proprietários de pesqueiros legalizados perante a lei, no entanto, ao avaliar com os pesqueiros pelos pesquisadores em conformidade com a legislação, mais que 60\% deles, encontram-se irregulares (CÓDIGO FLORESTAL, Lei 12.727 de 2012, em seu Art. $4^{\circ}$ ).

\section{CONCLUSÃO}

Conclui-se que as ações antrópicas nas APP são prejudiciais para o meio ambiente, impactando diretamente na paisagem natural da fauna, flora, recursos hídricos e da biodiversidade, bem como da sociedade, como averiguado na Rodovia do Peixe (universo de estudo), um exemplo recente, dentre muitos, que têm sido modificadas pelas ações do homem.

A Rodovia do Peixe implantada pelo governo do Estado como ponto turístico para atender ao município de Rondonópolis e regiões vizinhança, tem provocado intensas degradações ao meio biótico ocasionadas pelas atividades antrópicas. Estas ações ocasionadas pelo homem têm impactado negativamente os limites tolerados pelo Código Florestal Brasileiro com a implantação do empreendimento, causando desequilíbrio ao meio biótico. Nota-se ainda, que os impactos ambientais antrópicos geram degradação na fauna e vegetações nativas as margens do rio, prejudicando o meio ambiente ocasionados pelos processos erosivos, assoreamentos, enchentes, devastações de pragas e doenças decorrentes das eliminações dos resíduos sólidos domésticos em lugares 
Nestas condições, detectou-se in loco de acordo com os pesquisados que, com a os alimentos jogados para os peixes pelos pescadores tem provocado fermentação em lugares onde as águas são mansas do rio; cheiro desagradável; coloração diferente de outras localidades do rio; devastação da mata nativa nas margens do rio; desmoronamento dos barrancos do rio; assoreamento do rio. Condicionado a isto, encontram-se um rio que abastece a cidade de Rondonópolis, bem como serve de laser aos usuários, onde os pescadores e visitantes, podem interagir com a natureza, que, por conseguinte, devido à falta de preservação ambiental e social da localidade prejudica de forma danosa, as pessoas e o meio ambiente.

Assim, em face da importância do Rio Vermelho, que abastece a cidade de Rondonópolis e regiões, faz-se necessário, a minimização dos impactos negativos oriundos das atividades antrópicas, para melhorar a biodiversidade, fauna e flora, a qualidade de vida da população e da qualidade da água e peixes consumidos pela sociedade. Estas são condições são possíveis, com o empenho dos governos municipal e estadual, no sentido de fiscalizar a aplicação da lei, além de fiscalizar o cumprimento da preservação e respeito ao meio biótico, bem como disposição correta dos resíduos sólidos e efluentes de Rondonópolis e das propriedades remetidas ao longo da Rodovia do Peixe. Em face do exposto, essa pesquisa requer um estudo aplicado em todos os pesqueiros, com visões interdisciplinares, bem como alinhados a outros tipos de abordagem que avalie cada impacto ambiental de forma.

\section{REFERÊNCIAS}

AB'SABER, Naziz N. Os domínios de natureza no Brasil: potencialidades paisagísticas. São Paulo: Atehê Editorial, 2003. 160p.

ALBERT, Elaine P. Varela; CARNEIRO, Alex Pires; KAM, Lin. Recuperação das Áreas Degradadas Por Disposição De Resíduos Sólidos Urbanos. Diálogos \& Ciência -- Revista Eletrônica da Faculdade de Tecnologia e Ciências de Feira de Santana. Ano III, n. 5, jun. 2005.

AMARAL, Eni Aparecida; Pereira; GONÇALVES Saulo; BORGES, Daniela Cristina Silva. Avaliação de impactos ambientais em uma área de preservação permanente no bairro Céu Azul, Patos de Minas-MG, Minas Gerais, n. 4, p. 20, nov. 2013.

BRAGA, Roberto. Planejamento urbano e recursos hídricos. In: BRAGA, Roberto; CARVALHO, Pompeu Figueiredo de. (Org.) Recursos Hídricos e Planejamento Urbano e Regional. Rio Claro: LPM/DEPLAN/IGCE - UNESP, 2003.

BRASIL, Ministério do Meio Ambiente, Conselho Nacional de Meio Ambiente, CONAMA. Resolução CONAMA no 001 de 23 de janeiro de 1986. In: Resoluções, 1986. Disponível: http://www.mma.gov.br/port/conama/legiabre.cfm?codlegi=23.

BRASIL, Secretaria de Estado do Meio Ambiente, Departamento de Proteção da Biodiversidade. Cadernos da Mata Ciliar/- N 1 (2009). São Paulo : SMA, 2009. Disponível: http://arquivos.ambiente.sp.gov.br/municipioverdeazul/2013/05/Cadernos-de-Mata-Ciliar1_Preserva\%C3\%A7\%C3\%A3o-e-recupera\%C3\%A7\%C3\%A3o-de-nascentes_2004.pdf. Acesso em:14 abril de 2016. 
BRASIL. Lei 12.651/2012. Proteção da vegetação [on line]. Disponível em: <http://www.planalto.gov.br/CCIVIL_03/_Ato2011-2014/2012/Lei/L12651compilado.htm

$>$. Acesso em: 14 abril de 2016.

BRASIL. Lei No 4.771, DE 15 DE SETEMBRO DE 1965. [on line] Código Florestal Brasileiro. Disponível em: http://www.planalto.gov.br/ccivil_03/leis/L4771impressao.htm. Acesso em: 14 abril de 2016.

CACHEFFO, Patrícia. Meio Ambiente: Esgoto de estação elevatória atinge o Rio Vermelho. A Tribuna, Rondonópolis-MT, 21 set. 2016. Disponível em: <http://www.atribunamt.com.br/2016/09/esgoto-de-estacao-elevatoria-atinge-o-riovermelho/>. Acesso em: 29 set. 2016.

CAPPELli, S. PNMA: 30 anos da Política Nacional de Meio Ambiente. Homenagem à Professora Helita Barreira Custódio. São Paulo: Imprensa Oficial do Estado de São Paulo, 2011, p. 80.

DETRAN. Governo inaugura MT 471 e asfalto de avenida em Rondonópolis. 2009. Disponível em: http://www.detran.mt.gov.br/noticias/253/governo-inaugura-mt-471-e-asfaltode-avenida-em-roo. Acesso em: 14 abr. de 2016.

DOTTO, S. E. Os Ritmos, as Paisagens e a Qualidade da Água na Bacia do Rio Tadarimana, MT. - Mato Grosso. 2009. 169 f. Dissertação (Programa de Pós-Graduação em Geografia) - Universidade Federal de Mato Grosso, Cuiabá - MT, 2009.

FARIAS, T. Q. A edificação urbana à margem de rios e de outros reservatórios de água em face do código florestal. In: Âmbito Jurídico, Rio Grande, n. 37, p. 4-5, 2007.

FONSECA, J.J.S. Metodologia da pesquisa Científica. Apostila. Fortaleza: UEC, 2002.

LEUZINGER, M.D. A importância do Código Florestal no Quadro Normativo Ambiental Brasileiro. In: SILVA, S. T. et al (org.). Código Florestal: desafios e perspectivas. São Paulo: Editora Fiúza, 2010.

MMA - Ministério do Meio Ambiente. Áreas de preservação Urbana. Disponível: http://www.mma.gov.br/cidades-sustentaveis/areas-verdes-urbanas/\%C3\%A1reas-deprote\%C3\%A7\%C3\%A3o-permanente.Acesso: 20/12/2015.

MORAES, J. F. L.; CARVALHO, Y. M. C.; PECHE FILHO, A. Diagnóstico agroambiental para gestão e monitoramento da bacia do Rio Jundiaí Mirim. Jundiaí: Instituto Agronômico de Campinas, 2002. 108p.

OLIVEIRA, Cecília Gabriela S. de; PEREIRA, Saulo Gonçalves. Impactos Ambientais em uma Área De Preservação Permanente no Bairro Santa Cruz II em João Pinheiro/MG: Uma proposta de Educação Ambiental. Revista Educação Ambiental em Ação, 2016. Disponível em: http://www.revistaea.org/pf.php?idartigo=2895. Acesso em: 28 out. 2016. 
SILVA, Fernanda Pereira, BERRÊDO, Valéria Cristina Menezes, OLIVEIRA, Adenilce Ferreira de, JÚNIOR, Waine Teixeira, SANTOS, Débora Aparecida da Silva; Silva, Michele Salles da. Avaliação de Impacto Ambiental: Análise dos Indicadores Socioambientais na Implantação do Veículo Leve Sobre Trilhos (VLT). Interdisciplinar: Revista Eletrônica da UNIVAR, n. 14, v.2 Págs.72-78, 2016.

SIQUEIRA, Débora. Governo recebe pedido de pavimentação e obras de drenagem. 19 mar. 2015. Disponível em:<http://www3.mt.gov.br/editorias/politica-governo/governo-recebepedido-de-pavimentacao-e-obras-de-drenagem/138077> . Acesso em: 27 out. 2016.

SILVA, Valéria Cristina Ferreira e. A exploração dos Recursos Litológicos na Região da Cidade de pedra, Rondonópolis-MT. 116f. Dissertação de Mestrado. Universidade de São Paulo (USP). Curso de Pós-Graduação em Arqueologia, 2005.

SOARES, Thiago Santiago; CÔRTES, Mariana Aparecida Soares; FREITAS, Angelina Dornelas e VASCONCELOS, Fernanda Carla Wasner. Avaliação dos impactos ambientais na área de influência direta do córrego da Estiva, município de Betim, MG, Brasil. Revista do Centro de Ciências Naturais e Exatas, v.38 n.2, 2016, Mai.- Ago. p. 620 - 636.

SOUZA, André Vinícius Valuz de; OLIVEIRA, Simoni Maria Loverde. Análise da Qualidade da água do Rio Vermelho em Mato Grosso: no período de cheia no ano de 2014. Revista BIODIVERSIDADE. Mato Grosso. v.13, n. 2, p. 115 -126. 2014.Dísponível em: <http://periodicoscientificos.ufmt.br/ojs/index.php/biodiversidade/article/view/1960>.

Acesso em: 14 abr. de 2016.

SCHÄFFER, Wigold Bertoldo; Áreas de Preservação Permanente e Unidades de Conservação $\&$ Áreas de Risco. O que uma coisa tem a ver com a outra? Relatório de Inspeção da área atingida pela tragédia das chuvas na Região Serrana do Rio de Janeiro. Brasília: MMA, 2011. Disponível em:

http://www.mma.gov.br/estruturas/202/_publicacao/202_publicacao01082011112029.pdf >. Acesso em: 28 out. 2016.

TRIVIÑOS, A. N. S. Introdução à pesquisa em ciências sociais: a pesquisa qualitativa em educação. São Paulo: Atlas, 1987.

SÁNCHEZ, Luiz Enrique. Avaliação de impacto ambiental: conceitos e métodos. São Paulo: Oficina de Textos, 2008. 